\title{
A morte como acontecimento semiótico
}

\section{Death as a semiotic event}

\author{
Bruno Pael dos Santos \\ brunopael@gmail.com \\ Universidade Federal da Grande Dourados \\ Rita de Cássia Aparecida Pacheco Limberti ${ }^{* *}$ \\ limberti@hotmail.com \\ Universidade Federal da Grande Dourados
}

\begin{abstract}
RESUMO: A morte é uma certeza. Entretanto, passamos toda a nossa existência tentando evitá-la. Sendo a linguagem o processo simbólico que nos torna capazes de compreender e significar a realidade, o termo morte paira como um elemento irrepresentável, um vácuo de sentido, destinatário de inúmeros investimentos semânticos que buscam preenchê-lo. Assim, realizou-se pesquisa bibliográfica da teoria Semiótica Greimasiana e de outras ciências como a Sociologia e a Psicologia objetivando contemplar reflexões acerca dos desdobramentos culturais que impactam sobre os termos vida e viver e sobre o modus vivendi do homem através da história, como a maneira que ele avalia o significado de viver/morrer, suas produções culturais em torno da morte e a mudança de seus objetos de valor durante a narrativa chamada "Vida". Como principal resultado da pesquisa obteve-se melhor compreensão sobre a produção de efeito de sentido que o termo morte causa para o conceito de vida.
\end{abstract}

PALAVRAS-CHAVE: Morte. Significação. Semiótica.

ABSTRACT: Death is certain. However, we spend our existence trying to avoid it. Since language is the symbolic process that makes us capable of understanding and signifying reality, the concept of death stands as an unrepresentable element, a meaning void, a receiver of numerous semantic investments that seek to fulfill it. Thus, a bibliographical research of the Greimasian Semiotics theory and other sciences such as Sociology and Psychology was carried out aiming to prompt reflections on the cultural unfoldings that impact the concepts of life and living and the modus vivendi of human beings through history, such as the way they evaluate the meaning of living/dying, their cultural productions around death and the change of their valuables during the narrative called "Life." The main result of our research is that we better understand the production of meaning that the term death causes to the concept of life.

KEYWORDS: Death. Significance. Semiotics.

\footnotetext{
* Graduado em Psicologia e mestre em Letras (área de Linguística e Transculturalidade) na linha de pesquisa de Estudos de Língua(gens) e Discurso pelo Programa de Pós-Graduação em Letras da Universidade Federal da Grande Dourados

Doutora em Linguística - Semiótica e Linguística Geral e pós-doutora em Análise do Discurso. Docente e orientadora do Programa de Mestrado em Letras, da Faculdade de Comunicação, Artes e Letras da Universidade Federal da Grande Dourados
} 


\section{Introdução}

"Só temos duas vidas. A segunda começa quando nos damos conta de que só temos uma".

(Epicuro)

Há muito tempo a morte é algo que ocupa o pensamento humano, não só da população comum, mas também de grandes pensadores. A frase de Epicuro, nascido em 341 a.C. e falecido em 270 a.C., com quase 70 anos, epígrafe deste texto, resume de forma bastante precisa a forma como a percepção da morte oferece sentido à vida.

Ao adquirirmos consciência de nossa finitude, também ganhamos a noção de nossa limitação. Kovács (1992) afirma que as elaborações sobre a morte, os temores relacionados a ela, derivam diretamente do contexto sócio-cultural e histórico onde o indivíduo está inserido. Há em comum, entre todas as culturas, a limitação de tempo que a morte representa, a qual parece incitar a reflexão sobre o que fazemos em vida, dando sentido a ela. Muitas das escolhas dos humanos são influenciadas pela ideia de finitude. De uma forma geral, todas as atividades mais básicas como higiene, alimentação, sono, trabalho, sexo, são práticas de manutenção da vida, ou seja, em um sentido mais primitivo, de afastamento da morte.

Este trabalho pretende investigar os possíveis desdobramentos discursivos que o termo "morte" pode causar no universo de valores de um indivíduo inserido em nossa cultura. Mais especificamente, visam-se identificar os aspectos linguísticos envolvidos nas representações culturais da morte e investigar a relação dessas representações com a produção de valores, crenças, normas e percepções sobre a vida.

De acordo com Batistote (2012), em meados do século $X X$, as teorias que levam em consideração as relações linguagem/pensamento e linguagem/sociedade começaram a ganhar mais importância. Ela afirma que a partir desse momento da história o estudo da significação adquire uma importância maior que os das formas linguísticas pelo fato de os estudos linguísticos mobilizarem sua exterioridade, isto é, o sujeito, a história, o mundo.

O homem é subjetivo por excelência e buscou elaborar maneiras de administrar e dar sentido ao morrer. Sua representação da vida, as crenças geradas 
para revestir de significação os seus atos e os fatos da realidade inerentes ao viver são intrínsecas à linguagem. A religião, por exemplo, configura-se como a possibilidade simbólica de lidar com a morte, que alivia o insuportável. Crenças religiosas, nesse contexto, seriam tentativas humanas de simbolizar a morte na forma de linguagem. "Cada sociedade pode desenvolver uma ideia característica do que a morte é baseando-se em sua combinação particular de condições de vida [...] e em sua resposta às circunstâncias da morte [...]" (KASTENBAUM; AISENBERG, 1983, p.154).

Nesse contexto, Callia (2005) afirma que com o passar do tempo o homem criou artifícios culturais para lidar com o tema "morte". Ritos, celebrações e rezas, por exemplo, são tentativas de lidar com ela. O sepultamento apresentou-se como um dos primeiros sinais de civilização da humanidade.

Kovács (1992) afirma que desde períodos em que homens faziam suas pinturas rupestres em cavernas, ele representava a morte com ambivalência. Ao mesmo tempo em que se referia a ela como desintegração, ruptura, degeneração (se considerarmos o aspecto biológico implicado no processo de morrer e deteriorarse) também a registrava como sedução, entrega, alívio ou viagem (quando se pondera sobre a curiosidade da aproximação de um evento desconhecido como este, a cessação da resistência aos percalços da vida ou a possibilidade de se encontrar em outro espaço-tempo situado num "além-vida").

Consideramos interessante investigar a crença num além-vida enquanto esforço cultural em representar a morte pelo fato de que tal crença interfere na maneira como se significam os modos de vida, ou seja, existem consequências culturais geradas por tais representações. Compreender a forma como a morte é significada e a hipótese de sua naturalidade e inexorabilidade contribui para identificação e ponderação sobre significação da vida, possibilitando reflexões quanto ao que é considerado bem-viver e mesmo sobre o que se constitui como princípios de valores que embasam julgamentos de fatos/comportamentos como sendo éticos e/ou morais.

De acordo com Greimas (1966), a significação está universalmente presente e se apresenta de diversas formas. Para este autor, o mundo humano pode ser definido essencialmente como um "mundo de significação". Segundo essa afirmação, pode-se inferir que toda a significação que compõe o mundo humano, seus anseios, seu modo de vida, crenças, medos, sua tecnologia, psicopatologias, 
noções de saúde, etc. são fundamentadas em como o ser humano significa sua experiência com a realidade. Daí a possibilidade de estudar as representações da morte e, consequentemente, a significação da vida, por um viés linguístico e como fenômeno da linguagem, objetivando melhor compreensão sobre a produção de efeito de sentido que os revestimentos semânticos do termo morte conferem ao termo vida.

\section{Realidade, linguagem, morte e cultura}

"As fronteiras da minha linguagem são as fronteiras do meu universo"

(Ludwig Wittgenstein)

Wittgenstein (2014) fez interessante ponderação sobre a relação realidade/linguagem. Ele afirmou que a realidade não é dada ao Homem, mas ela é para o Homem resultado de interpretações linguísticas, leituras que este faz da realidade. O Homem, ao reproduzir a realidade por meio da língua, produz uma versão dela. Assim, as informações que se apreendem da realidade se tornam "projeções das estruturas linguísticas dadas primariamente, com as quais nós falamos sobre o mundo" (KUTSCHERA, 1971, p.134). Fazemos para nós uma imagem da realidade. "A psicologia cognitiva também entende como uma imagem a reprodução mental ou representação de uma experiência perceptiva não-presente (SANTAELLA, 2015, p.31).

Pelas definições acima, pode-se inferir que a proximidade que o Homem tem com a morte, enquanto fato da realidade, são as "versões" que faz dela pela representação linguística e de imagens mentais, ou seja, representações de uma experiência perceptiva de um fato não presente. Entretanto, há ainda um aspecto importante a ser mencionado. O indivíduo não pode representar por meio da linguagem a própria morte, pois ele não a experiencia. Ao menos não a morte em seu sentido "médico", quando seu corpo para de funcionar. Nesse aspecto, Epicuro diz que a morte nada representa para nós, pois quando existimos, ela não existe. Quando ela existe, já não existimos mais. Assim, o que o indivíduo experiencia e representa para si é a morte do outro.

A morte se apresenta como uma incógnita, como se quem morresse passasse por uma barreira que repele qualquer ser vivo e o impede de observar o 
que está adiante, mesmo que pela fresta da porta que se fecha atrás do morto. A morte irrompe. O homem, entretanto, procurou meios de imaginar o que vem depois dessa barreira e de tentar representar o que não lhe foi apresentado. A religião, os ritos, as cerimônias fúnebres - como os velórios - podem ser entendidos como algumas dessas tentativas. Culturas diferentes lidavam com a mortalidade/imortalidade de formas diferentes.

O Peru praticou muito a mumificação [...]. O morto, preparado com suas mais belas vestes, deve chegar ao além munido de seus bens [...]. O corpo, dobrado e agachado, joelhos encostando no queixo, antebraços dobrados ou em volta dos joelhos, imita a posição do feto (BAYARD, 1996, p.119).

Aparentemente os peruanos correlacionaram a morte com o nascer ou, talvez, desnascer, quando colocaram seus mortos em posição fetal. É interessante observar a possibilidade de a morte ter sido representada como renascimento ou como o retorno ao lugar onde supostamente as pessoas estariam antes de nascer.

Tem-se a ideia de que a morte é o capítulo final comum às narrativas de todas as pessoas, mesmo que estas narrativas sejam todas diferentes, individuais. Ao considerarmos a vida como narrativa, retomamos o campo de estudo da Linguagem, principal pilar dos estudos que serão desenvolvidos no decorrer deste artigo.

Ao mencionar a palavra "semiótica" podemos enumerar vários estudiosos que dedicaram suas obras ao tema. No entanto, é no trabalho de Algirdas Julien Greimas que identificamos o espelho necessário para obter uma imagem plausível da morte (ou pelo menos um esboço) ao projetar sobre ele os questionamentos quanto à significação (ou a ausência de significação) da palavra morte e de tudo o que dela pode derivar.

A teoria semiótica proposta por A. J. Greimas, também chamada de Semiótica Discursiva, tem sua origem atribuída à obra Semântica Estrutural - pesquisa de método (1966). O livro, embora trate do "parente pobre" da Linguística - forma como o autor se refere à Semântica -, seria o embrião para o que se chamou, anos mais tarde, de Semiótica.

Greimas teve como foco identificar os processos de significação para as Ciências Humanas. Segundo ele, o questionamento quanto ao sentido das atividades realizadas pela humanidade se constitui como uma leitura de mundo, 
como, por exemplo, um inventário de comportamentos gerado pelos estudos antropológicos ou uma série de acontecimentos ocorridos num determinado tempoespaço, registrados e categorizados sistematicamente por historiadores. Para que um fato, externo à nossa percepção, seja considerado humano, ele precisa significar algo (GREIMAS, 1966).

Greimas e Courtés (2008) afirmam, ainda sobre o conceito da semiótica, que esta é uma teoria da significação. Sua função principal é explanar de maneira conceitual quais as condições para que ocorra a apreensão de sentido. Em se tratando de processos de significação, a percepção se apresenta como o elemento básico e primordial inerente a todas as formas de engendramento de sentido, tema também tratado por Greimas. A percepção seria considerada como um ambiente "não linguístico onde se situa a apreensão da significação" (GREIMAS, 1966, p.15).

Aqui se apresentam semelhanças com teorias pertinentes ao campo da Psicologia. Para a Psicologia Cognitiva, "a percepção se define pelo conjunto de processos pelos quais reconhecemos, organizamos e entendemos as sensações recebidas dos estímulos ambientais" (STERNBERG, 2000, p.110). Assim, um objeto, por si só, não tem sentido. Ele precisa da percepção do Homem que, por sua vez, se baseia em suas experiências e conhecimentos adquiridos através da linguagem para que possa revestir o objeto de sentido, de significação, ou seja, para que haja sobre ele o efeito de sentido. Fora da linguagem não existe significado porque é a linguagem que media a percepção. Um objeto e um texto adquirem significação a partir do momento em que incidem sobre eles os constructos realizados pelo homem, que são elaborados através da linguagem. Daí a possibilidade de estudar a morte pelo campo da Linguagem.

Podemos aqui inferir que a Semiótica oferece aparato teórico-metodológico valioso para a compreensão de como nossa percepção de mundo proporciona interpretação coerente para que a realidade externa (e vazia de sentido) seja preenchida com sentido.

A vida pode então ser como uma narrativa. Em Barros (2010) encontra-se outra definição pertinente:

O enunciado elementar da sintaxe narrativa caracteriza-se pela relação de transitividade entre dois actantes, o sujeito e o objeto. A relação define os actantes; a relação transitiva entre sujeito e objeto dá-lhes existência, ou seja, o sujeito é o actante que se relaciona transitivamente com o objeto, o objeto é aquele que mantém laço 
com o sujeito. Há duas diferentes relações ou funções transitivas, a junção e a transformação [...].

Enunciado de estado: $F$ junção (S.O)

Enunciado de fazer: $F$ transformação (S.O)

$F=$ Função $\quad S=$ Sujeito $O=$ Objeto (BARROS, 2010. p.17)

Pode-se, então, fazer a seguinte relação entre $\circ$ Homem e o objeto vida/sobrevivência. O Sujeito (S) se relaciona transitivamente com o Objeto de Valor (O ou Ov) vida/sobrevivência. Viver pode ser considerado como a obsessão do Homem que, mesmo ciente de sua finitude, pretende ser imortal. De acordo com Morin (1997), o homem nega a morte como aniquilamento e aceita-a apenas como acontecimento. Durante sua existência, quando realiza atividades de manutenção da vida, quando se alimenta, se protege e até mesmo se coloca numa projeção que vai além de sua morte, o homem elabora maneiras de manter-se vivo em algum espaço metafísico como meio de escapar à sua aniquilação. É neste ponto que adentramos aquele que pode ser considerado o maior impacto cultural que a morte nos proporcionou: a religião, a qual se configura como a hipótese fantasística mais estável quando o intuito é oferecer uma resolução para aquilo que tentamos evitar ao máximo.

Embora a morte seja um fato natural observável - o que lhe confere caráter material -, uma das características da morte é justamente a perda da matéria, da materialidade. Podemos pensar que a matéria se transforma, mas o status que ela tem, o que a caracteriza naquele momento como, por exemplo, a personalidade de alguém, sua identidade, ou seja, o que dá o status de pessoa a um corpo se perde, se desfaz, ao menos na realidade observável.

Infelizmente (ou felizmente) não podemos observar o que acontece depois da morte. Aliás, tudo o que se pode observar sobre esse evento é o que acontece com o outro, pois como foi citado anteriormente, não podemos experienciar nossa própria morte. Somos então, por muitas vezes, vítimas de imensa agonia e, ao mesmo tempo, de grande curiosidade por não podermos observar tal certeza de forma objetiva e dar-Ihe significação.

\section{Cultura e discurso}

Consideramos interessante realizar leve empréstimo teórico à Análise do Discurso para apontar algumas evidências. Segundo a noção de relação de 
sentidos, todo discurso é necessariamente relacionado a outros. É a enumeração de outros discursos um dos fatores que contribuem para o sentido. "Um dizer tem relação com outros dizeres realizados, imaginados ou possíveis [...] as palavras não têm sentido nelas mesmas, elas derivam seus sentidos das formações discursivas em que se inscrevem" (ORLANDI, 2015, p.37 e p.41).

Assim, delinear o sentido da morte se apresenta como um processo sociocultural que se estrutura primeiro nas interpretações subjetivas que já foram realizadas sobre o evento durante a história e, depois, pela reprodução desses discursos construídos e reconstruídos ao longo dos tempos. Ora, rituais fúnebres -e temos uma gama bastante substancial deles - não são naturais nem foram deixados para nós por deuses. Rituais são elaborações que construímos e mantemos culturalmente.

O conceito de cultura tem vários significados. Há aqueles que o entendem como o desenvolvimento de elaborações humanas, tornando práticas e obras artísticas manifestações desse desenvolvimento (CANEDO, 2009). "A cultura [...] é a soma dos saberes acumulados e transmitidos pela humanidade, considerada como totalidade, ao longo de sua história" (CUCHE, 2002, p.21). Temos ainda que a cultura se fundamenta e se mantém "através da interação social dos indivíduos, que elaboram seus modos de pensar e sentir, constroem seus valores, manejam suas identidades e diferenças e estabelecem suas rotinas" (BOTELHO, 2001, p.2),

Dessa forma, podemos inferir que a assunção, interpretação e articulação dos axiomas balizadores da intenção de significar, representar ou apreender a morte são resultados de produções seletivas restritivas, sejam elas individuais ou coletivas, elaboradas sobre o tema.

\section{Visões culturais da morte através da História}

Naturalmente que todos os processos envolvidos no ato do falecimento não poderiam ser descritos aqui de forma detalhada. Portanto, biologicamente, de forma bastante breve, morrer dura alguns segundos. No máximo, minutos. $\mathrm{O}$ organismo começa a morrer quando um de seus órgãos para de funcionar, vai à falência, a qual vai se espalhando pelo corpo até que os tecidos desse organismo se paralisem. Depois as células paralisam também e o corpo entra em decomposição e se transforma em pasta. Depois gases e, finalmente, pó (KELLEHEAR, 2016). 
De acordo com Kellehear (2016), na alvorada da existência do ser humano, era parte de seu cotidiano caçar e colher alimentos da natureza. Os agrupamentos humanos eram nômades e estavam expostos aos mais variados perigos como predadores, ambientes insalubres, falta de abrigo seguro e mesmo acidentes que podiam acontecer durante a migração para outros lugares, de forma que a vida tinha maiores chances de terminar abruptamente pelas razões mencionadas.

Apesar dessas ameaças, os instrumentos construídos pelos nossos ancestrais, como armas de pedra e madeira, ajudou-os a sobreviver aos predadores e a se alimentar. A melhora da comunicação ajudou-os a conviver com seus iguais, favorecendo a caça em grupo e o fortalecimento dos humanos como comunidade (BINGHAM, 1999). Klein (2009) afirma que os humanos da Idade da Pedra tinham expectativa média de vida de 36 anos. Quando muito, chegavam a viver 50 anos. Morria-se por uma combinação de doença, desnutrição e traumas físicos.

A prática do sepultamento aparentemente não existia nessa época. Aliás, o sepultamento apresenta-se como um dos primeiros traços civilizatórios de qualquer civilização - após a linguagem, que é o primeiro - ou seja, um local que apresentava vestígios de que fora habitado pelo homem e onde se encontravam ossadas humanas dispostas de modo organizado, que indicavam sepultamento, significava que aquele grupo estava iniciado na linguagem (produção e busca de sentido), portanto, já começava a elaborar significados para um cadáver, para um corpo morto, para a morte. Se antes o homem permanecia indiferente a um semelhante que caía morto a seu lado e partia deixando-o ao relento, a entrada na linguagem fez com que ele passasse a experimentar estados de alma diante do corpo morto, buscando expressá-los e tentando elaborar sentidos para a morte. A partir da entrada na linguagem - que é busca e produção de sentido - o homem não pode mais ficar indiferente a nada: Um novo mundo lhe é desvendado, matizado pelos sentidos. A morte, contudo, permanece pétrea em sua inacessibilidade semântica. Impenetrável, perturbadora, começa a receber investimentos, revestimentos, volteios imaginários e fantasísticos.

Além de todas as evidências apresentadas sobre a possibilidade de que o sepultamento data de períodos bastante antigos, devemos ainda mencionar as pinturas rupestres nas cavernas. As cavernas eram utilizadas pelos humanos dessa época de várias maneiras. A mais elementar era como abrigo, mas podemos ainda citar outras como sua utilização para rituais, expressão (pinturas), depósito, local 
para realização de cultos e, por fim, sepultamento dos mortos (BONSALL; TOLANSMITH, 1997).

De acordo com Kellehear (2016), há indicações de que as pessoas que viveram na Idade da Pedra tinham a crença de que a morte fosse outro tipo de vida, demonstrando que nossos ancestrais empreendiam esforços para que, assim como ainda fazemos nos dias atuais, à nossa maneira, dar algum sentido ao evento da morte e do morrer.

$\mathrm{Na}$ Idade do Bronze, morrer era um processo que era iniciado com o evento da morte, como se falecer fosse um evento que iniciasse o afastamento progressivo entre os que aqui ficaram e o que partiu, na medida em que o morto ia sendo "esquecido" com o passar do tempo. Lucas (1996) afirma que as pessoas passavam por um processo de "ancestralização", dividido em três etapas. A primeira etapa consistia no sepultamento do falecido; a segunda, na decomposição e no desmembramento ou mesmo na quebra dos ossos; a terceira era caracterizada pela remoção dos ossos do local do sepultamento e o transporte destes restos mortais para outro local, como, por exemplo, a entrada da residência da pessoa falecida.

Parece sensato ponderar sobre a possibilidade de que, segundo a interpretação de nossos ancestrais, morrer (como ato contínuo à morte biológica) consistia no desapego em relação à pessoa falecida. Assim, sua morte deflagrava nos sobreviventes o sentimento de luto e a interpretação para esse sentimento e para a ausência do falecido, era de que ele, agora que estava se desintegrando e progressivamente deixando os demais para trás, estava efetivamente morrendo. Em outras palavras, o morrer para os sobreviventes da época seria o paulatino desvanecimento da presença - e não se trata apenas da presença física, mas do lugar social - daquele que lentamente perde seu corpo físico e adentra relativo esquecimento.

Assim, podemos inferir que ocorreu na Idade da Pedra o nascimento de parte importante das crenças que se sucederam (religiosas e não religiosas) sobre a morte e o morrer: a presunção de uma existência pós-morte, pilar basal para todos os desdobramentos culturais que viriam a decorrer da rejeição subjetiva da possibilidade de aniquilação, como resposta à grande interrogação na qual jaz nossa própria finitude.

Mais tarde, há cerca de 12 mil anos, houve um grande acontecimento que mudou drasticamente a forma como os humanos viviam: o surgimento da 
agricultura. Nesse momento a linguagem estava mais desenvolvida e os humanos começaram a se assentar, deixando de migrar (LARSON, 1995). Surgiam as sociedades pastoris, seguidas de pequenas fazendas, aldeias e, posteriormente, das cidades.

É de se refletir sobre a possibilidade de que o modelo de sociedade tal qual conhecemos hoje, aglomerado e com sua funcionalidade, tenha surgido pelo instinto de sobrevivência instalado em nós que fez com que, na intenção de diminuirmos os riscos de morte, passássemos a nos agrupar, diminuindo os riscos no combate com as caças, a nossa vulnerabilidade em relação aos predadores e reduzindo a probabilidade de sermos mortos ou feridos em atividades em campo aberto através do cultivo de alimentos. Em outras palavras, pode-se conjecturar que as cidades não existiriam, não fosse nossa insistência em resistir à morte.

O fato é que, naquela época, graças a essa mudança de nômades para assentados, as pessoas começaram a sobreviver por mais tempo e, por essa razão, podiam ver a morte se aproximar mais lentamente. Scarre e Fagan (2003) expõem que uma das possibilidades para que tenhamos passado a nos fixar em algum território pode advir do apego a uma região por motivos religiosos ou familiares. Outros motivos possíveis são o fim da Era Glacial, que oportunizou o surgimento de ervas em regiões onde até então eram ausentes, o surgimento de locais férteis em vales propícios à agricultura e que podiam manter maior número de pessoas. Assim nasceram as aldeias e cidades (LEWIN, 1999; DANIEL, 2003).

Com todas estas mudanças sociais e culturais, a morte passou a ser menos abrupta. Morria-se mais "lentamente". Assim, algumas diferenças também se estabeleceram na forma como as pessoas se relacionavam em torno do morrer. Elas agora tinham mais tempo para passar ao lado do moribundo, tendo a chance de rezar junto dele, conversar, tentar algum tipo de remédio e oferecer cuidados paliativos. Aqui ainda existia a ideia de morte como viagem à ultravida. A diferença é que morrer, diferentemente do que acontecia na Idade da Pedra, passou a ser um acontecimento pré-morte, ou seja, passava a acontecer antes da morte biológica, não apenas uma experiência do além. Morrer, agora, passou a ser um rito de passagem importante (KELLEHEAR, 2016).

Esses rituais fúnebres também mudaram. Na Idade da Pedra, como a morte da pessoa ocorria mais repentinamente, todas as decisões relativas à morte dessa pessoa eram tomadas pelos que com ela conviviam. Assim, por exemplo, sua 
herança - ato que na época não se tratava de presentear os vivos com pertences dos mortos, mas de enterrá-los com ele - era providenciada pela família. Na Idade Pastoril os morrentes tinham tempo para tomar algumas decisões relativas ao seu falecimento, podiam tomar providências e tinham autonomia no que dizia respeito ao seu morrer, ou seja, nessa época, eles tinham certa voz sobre suas próprias mortes, inclusive participando de seus preparativos (KELLEHEAR, 2016).

Freud (2013) apresentava outra possível explicação para as razões do tratamento ritualístico dos mortos. Ele via que as raízes deste comportamento social não estavam no sentimento de ambivalência, mas no de culpa. Em geral, quando alguém falece, é comum o sentimento de que poderíamos ter feito mais por aquela pessoa enquanto ela estava viva e que, talvez, o excesso de preparativos seja uma maneira de compensação pelo que não foi feito em vida. Freud também sugeriu que uma das conotações para os ritos fúnebres é encenar uma morte sacrificial, o que faz sentido em muitos contextos religiosos, como o judaico-cristão, onde sacrifício tem importância (literalmente) vital.

\subsection{Morte na era da globalização}

Morrer nos tempos atuais parece algo bastante diferente de morrer nas eras anteriores. A frase anterior, naturalmente, implica a mensagem de que viver nos tempos atuais também é diferente. A grande mudança na história da humanidade, na Idade Pastoril, foi a agricultura. Em nossos tempos, foi a informação e seu compartilhamento. Embora a propagação de informação seja algo recorrente na natureza desde que a vida surgiu, uma vez que toda a reprodução dos seres vivos se baseia na transmissão de informações por meio do DNA, agora isso tem outra conotação. O boom tecnológico trouxe inovações no que se refere à saúde pública, transporte, meios de comunicação, produção alimentícia e desenvolvimento do capital. Atrelado a tudo isso, há o crescimento demográfico vertiginoso (KELLEHEAR, 2016).

Muitas das mudanças sociais que tivemos nas últimas décadas são resultado de revoluções na comunicação. O volume de informações disponíveis atualmente fornece materialidade para o levante de questionamentos relacionados aos papéis sociais, valores, hábitos individuais e coletivos, tradições culturais, etc. (GIDDENS, 2002). 
A religiosidade tem deixado de fazer parte do imaginário popular, embora ainda seja bastante presente (GILL; HADAWAY; MARLER, 1998). Quanto mais a sociedade se desenvolve, troca informações, mais produz conhecimento científico, avança na explicação de fenômenos que antes eram mistérios e - naturalmente interpretados metafisicamente, vemos a crença numa vida póstuma desvanecer lentamente. Há mais ênfase agora em empreender algum crescimento pessoal espiritual ou em encontrar-se com uma entidade que gratuitamente estende sobre nós imenso afeto (FOX, 2003).

Vale relembrar que a religião é o principal dispositivo elaborado por nós (até o momento) para significar a morte. Daí a importância em se observar o impacto que o desenvolvimento tecnológico e o tráfego intenso de informações produzem nesse contexto.

Voltando ao espectro da saúde, fator importante para compreendermos os mecanismos pelos quais a morte se cumpre, temos que a globalização contribui para a propagação de doenças assim como para que tecnologias direcionadas às suas curas se propaguem mais facilmente. $O$ fato é que podemos viajar facilmente para qualquer local do globo. Problemas epidemiológicos que antes estavam associados a uma região específica, hoje se dispersam através de hospedeiros viajantes. Diminuindo um pouco o espaço geográfico, uma doença pode vir a nós por um cônjuge infiel ou mesmo por meio de um encontro marcado na internet. Parece irrefutável a afirmação de que a circulação intensa de informações pelos meios de comunicação afetou a forma como vivemos e morremos.

Assim, observa-se que as características dos modos de vida experimentados pelo homem em cada período histórico moldam a maneira como se processa e se interpreta o seu morrer. E seu modo de morrer, da mesma forma, influencia seu modo de viver. Evidencia-se então a indissociabilidade inerente entre vida, morte e modo de viver, demonstrando assim os impactos que a morte tem sobre como agimos em vida.

\section{A religião em seu aspecto cultural: uma tentativa de escapar à aniquilação}

"A resposta ao enigma da morte acaba por se dar, geralmente, no âmbito da religião" (MURILLO, 1999, p.13). Aparentemente, a religião é uma tentativa de domar a morte. Ao mesmo tempo, a morte, no contexto da religião, também é 
dispositivo de controle e disciplina. Cobram-se condutas comportamentais em troca da vida eterna. A religião é a ponte que liga o indivíduo ao seu destino final, que pode ser bênção ou maldição, dependendo de suas atitudes e comportamentos manifestados em vida. Assim, mesmo no contexto religioso, ou seja, metafísico, a morte produz efeitos de sentido sobre como se vive. Então são criados valores do bem e do mal que normatizam e controlam o comportamento humano, os quais são aprovados ou reprovados socialmente.

A religião permeia grande parte da produção cultural da humanidade. Temos a impressão de que sua filosofia permanece estritamente em templos, sinagogas, igrejas, centros espíritas e terreiros e de que suas práticas não pertencem à vida cotidiana nem suas doutrinas se misturam a outros saberes. Entretanto, podemos ler já no preâmbulo da Constituição Federal Brasileira de 1988 os seguintes dizeres:

Nós, representantes do povo brasileiro, reunidos em Assembléia Nacional Constituinte para instituir um Estado Democrático, destinado a assegurar o exercício dos direitos sociais e individuais, a liberdade, a segurança, o bem-estar, o desenvolvimento, a igualdade e a justiça como valores supremos de uma sociedade fraterna, pluralista e sem preconceitos, fundada na harmonia social e comprometida, na ordem interna e internacional, com a solução pacífica das controvérsias, promulgamos, sob a proteção de Deus, a seguinte CONSTITUIÇÃO DA REPÚBLICA FEDERATIVA DO BRASIL (BRASIL, 1988).

Esse texto estabelece leis que, como todas as outras, norteiam a ação de determinado grupo social. Independentemente dos que creem ou não em alguma entidade divina, a presença de Deus em nossa constituição denota que nossa proximidade com o que é metafísico é tão grande que muitas vezes não nos damos conta. Há uma necessidade, enquanto sociedade, de que sejamos assistidos por algo que nos é externo, algo que nos controle, nos guie, nos dê forças e, por conseguinte, nos salve. Embora não tenhamos provas de que alguma entidade que exista em uma realidade presumida por nós esteja disposta a nos salvar, este é um pensamento bastante comum. E a principal promessa dessa crença é a de que, no fim, viveremos a vida eterna.

Essa esperança que a religiosidade traz apresenta influência dos pensamentos de Platão. "Embora os homens não o percebam, é possível que todos os que se dedicam verdadeiramente à filosofia a nada mais aspirem do que a morrer e estarem mortos" (IX, 64b), pois depois da morte, há algo "[...] muito melhor para os 
bons do que para os maus" (Fédon, VIII, 63c). Pressupõe-se uma recompensa para aqueles que vivem de acordo com normas sociais e morais estabelecidas no percurso do tempo, da história. Em geral, denota-se a negação do corpo, da carne, dos instintos e vontades individuais para, assim, ascender ao paraíso.

O tema morte era bastante presente na era medieval. Aliás, poder-se-ia afirmar o mesmo sobre nosso contexto atual. Entretanto, naquele momento histórico, produziu-se muito material sobre o assunto. Conciliando a fé e a filosofia, despontou o filósofo Tomás de Aquino. Aquino considerava a morte como uma consequência do mal moral. Para a religião judaico-cristã, o equivalente ao termo é o "pecado original”. Vale observar que a morte à qual o filósofo se refere não é apenas a do corpo, mas a negação da vida eterna, caso o crente escolhesse não seguir os desígnios de Deus, recusando uma vida de retidão. Nesse sentido, morrer representa ter cedido deliberadamente, em vida, a caminhos moralmente inaceitáveis. O homem, em sua visão, teria nascido com uma alma impossível de ser corrompida, porém em um corpo corruptível; e o que faz com que ele morra, biológica e metafisicamente, é não ser capaz de manter a inocência natural com a qual foi concebido. A morte do homem, aqui, não é vista como natural no que diz respeito à alma. E no tocante ao corpo, este perece por sua alma estar adoecida.

Avançando em direção ao momento atual, considerando-se, sobretudo, o protestantismo e o catolicismo brasileiros, há dificuldade no que diz respeito a produzir uma visão única e inequívoca sobre a morte quando se leva em conta a infinidade de religiões existentes em território nacional. Entretanto, buscou-se abordar aqui as religiões mais demograficamente expressivas.

"As ciências sociais, desde as suas origens na segunda metade do século XIX, têm mostrado preocupações com as representações elaboradas coletivamente a respeito da morte" (CAMPOS, 2009, p.113). Entre os pesquisadores da Antropologia, a morte adquire uma conotação de algo que traz certo caos, levantando questionamentos sobre a separação entre o que é considerado sagrado e profano, puro e impuro (CAMPOS, 2009).

A consciência que o ser humano tem sobre viver ciclicamente e morrer faz com que ele crie marcos para pontuar fases de sua vida. Assim, temos, em geral, que viver se trata de nascer, crescer, procriar, cuidar da prole e morrer. Em cada marco, fazemos investimentos culturais, construindo saberes e depreendendo aprendizados, passando adiante através das gerações, ou seja, produzimos 
fórmulas culturais que dão sentido à experiência de viver e que serão oferecidas aos nossos descendentes. A possível razão para isso é a necessidade - inerente à nossa condição de morrentes - de explicar o inexplicável. Compreendemos e acumulamos experiências de vida, mas a experiência de morte é algo que aparentemente nos é negado. Não é possível acumular nem transmitir a experiência de morte; portanto, no temor de nos depararmos com algo que não pode ser interpretado, criamos sentidos para a morte. Daí a erupção da religião como tentativa de significação.

Contrapondo-se à ideia que permeia o texto até aqui, de que os ritos fúnebres surgiram após o nascimento da religião, Coulanges (2003) oferece um ponto de vista diferenciado ao afirmar que a fixação de povos em determinado território - o assentamento de povos que antes eram nômades, discutido anteriormente - se deu pelo agrupamento de pessoas em torno de santuários ou sepulturas. Segundo ele, em estudos referentes aos povos indo-europeus,

As gerações mais antigas, bem antes que existissem filósofos, já acreditavam em uma segunda existência para além desta nossa vida terrena. Encarava a morte não como uma aniquilação do ser, mas como simples mudança de vida [...]. Acreditavam que quando se enterrava um corpo no túmulo, se acreditava enterrar junto algo com vida (COULANGES, 2003, p.13).

De acordo com o autor, para as culturas antigas, os mortos continuavam entre os vivos. Mais que isso, os vivos se organizavam em torno de seus mortos. As fogueiras eram acesas em volta das sepulturas e eram feitos banquetes. Os mortos estavam presentes, mesmo que invisíveis, e exerciam influência sobre seus descendentes. Algo dessa visão parece permanecer hoje em religiões praticadas no Brasil, como, por exemplo, a crença do Espiritismo de que espíritos são capazes de obstruir ou favorecer os caminhos dos vivos. Baseadas nisso, algumas culturas desenvolveram a crença na necessidade de agradar aos mortos na intenção de obter deles alguma benesse. Sob esse viés poderíamos ponderar, ainda, que o desenvolvimento de cerimônias ritualísticas seriam esforços que visavam à recompensa por parte dos falecidos, a garantir que caso estes não ajudassem, ao menos não atrapalhassem os vivos.

No Brasil, havia a crença cultural de que a morte marcava o início de uma extensa viagem. A função dos ritos era auxiliar os mortos a encontrar o caminho 
para a última morada. Decorre dessa crença a prática católica de enterrar as pessoas com uma vela acesa em suas mãos, para que a alma do morto tivesse alguma fonte de luz quando estivesse caminhando em território desconhecido. Fora do caixão ainda eram colocadas outras velas perto da imagem de Jesus na cruz. $O$ auxílio não era exatamente um ato de bondade. Esperava-se que o morto, após se encontrar com Deus, passasse a interceder pelos que aqui ficaram (CAMPOS, 2009).

O autor ainda faz interessante questionamento: para que servem os ritos? De acordo com ele, os ritos têm a função de facilitar a vida, "condensando significados; elementos carregados de sentido; momentos de dramatização social. Há um cenário, as falas, um script, uma movimentação" (CAMPOS, 2009, p.116). Os ritos eliminam as incertezas da vida. Eles são balizadores que demarcam pontos de passagem, dissipam dúvidas e oferecem aos humanos a reconfortante sensação de fruição, direção e sentido.

Enfocando novamente o contexto brasileiro da religião, Campos (2009) afirma que os evangélicos receberam considerável influência de outras culturas em seus 500 anos de história. Os católicos estavam mais bem amparados em seus ritos romanos. Os evangélicos, na ausência dessa elaborada ritualística, acreditam que o apego a Jesus é a maneira mais sensata de ascender ao paraíso. Não há, como para os católicos, um caminho a ser percorrido nem um local intermediário (como o purgatório) entre o mundo dos vivos e o céu ou o inferno.

O resultado dessas divergências, enfim, são visões bastante pluralizadas em relação à morte e ao morrer.

\section{Considerações finais}

Não é ainda tão simples significar o evento da morte, mesmo com o apoio da interpretação religiosa dos fatos. Na tentativa de dar sentido à finitude, criaram-se artefatos tão elaborados e detalhados que parecem mais confundir do que facilitar sua apreensão. Isso porque estão citadas aqui apenas algumas das religiões, uma vez que seria um tanto quanto dificultosa a tarefa de abarcar de maneira apropriada todas as culturas religiosas de forma clara, precisa e detalhada.

Assim, temos que a religião está intimamente conectada com a elaboração cultural que objetiva oferecer um destino menos doloroso do que ser destruído e ter 
nosso "eu" transformado apenas em memórias. A ideia de nunca mais ter a chance de ser "eu" novamente é algo que parece nos assustar profundamente e nos causa sofrimento.

Ao entrar na linguagem, o homem passou a perceber os fatos, fenômenos, seres e objetos do mundo natural, produzindo sentido neles. Tal elaboração de sentidos constitui-se o abrigo em que o homem se ampara para fazer face ao real e encontrar seu lugar como sujeito. A morte constitui-se no enigma primordial, num orifício sem bordas através do qual o homem vislumbra seu vazio existencial.

\section{Referências}

BARROS, Diana Luz Pessoa de. Teoria Semiótica do Texto. 4. ed. São Paulo, Editora Ática, 2010.

BATISTOTE, Maria Luceli Faria. Semiótica francesa: busca de sentido em narrativas míticas. Campo Grande: Editora UFMS, 2012.

BAYARD, Jean-Pierre. Sentido oculto dos ritos mortuários. Morrer é morrer? Trad. Benôni Lemos. São Paulo: Paulus, 1996.

BINGHAM, P.M. Human uniqueness: a general theory. Quarterly Review of Biology, v. 74, n. 2, 1999.

BONSALL, C; TOLAN-SMITH, C. (Org.). The human use of caves. British Archaeological Reports, International Series 667. Oxford: Archaeopress, 1997.

BOTELHO, Isaura. Dimensões da cultura e políticas públicas. São Paulo em Perspectiva, São Paulo, v. 15, n. 2, 2001.

CALLIA, Marcos H. P. Introdução. In: OLIVEIRA, Marcos Fleury de; CALLIA, Marcos H. P. (Org.). Reflexões Sobre a Morte no Brasil. São Paulo: Paulus, 2005.

CAMPOS, Leonildo Silveira. "Chamados à mansão eterna: Morte, ritos e visão pósmorte no protestantismo tradicional brasileiro". In: SANTOS, Franklin Santana (org). A arte de morrer - visões plurais. v. 2. Bragança Paulista, SP: Editora Comenius, 2009.

CANEDO, Daniele. "Cultura é o quê?" - reflexões sobre o conceito de cultura e a atuação dos poderes públicos. Artigo apresentado no $\mathrm{V}$ ENECULT - Encontro de Estudos, 2009. Disponível em: <http://www.cult.ufba.br/enecult2009/19353.pdf>. Acesso: 01 jul. 2018.

COULANGES, Fustel de. A cidade antiga. São Paulo: Martin Claret, 2003. 
CONSTITUIÇÃO DA REPÚBLICA FEDERATIVA DO BRASIL de 1988. Disponível em: <http://www.planalto.gov.br/ccivil_03/constituicao/constituicaocompilado.htm> Acesso: 01 jul. 2018.

CUCHE, Denys. O Conceito de Cultura nas Ciências Sociais. Trad. Viviane Ribeiro. 2. ed. Bauru, SP: EDUSC, 2002.

DANIEL, G. The First Civilizations: the archaeology of their origins. Londres: Phoenix Press, 2003.

FOX, M. Religion, Spirituality and the Near-death experience. London: Routledge, 2003.

FREUD, S. Totem and taboo. London: Routledge \& Kegan Paul, 1960. . Totem e tabu. São Paulo: Companhia das Letras; Penguin, 2013.

GIDDENS, A. Runaway World. Londres: BBC, 2002.

GILL, R.; HADAWAY, C. K.; MARLER, P. L. Is religious belief declining in Britain?. Journal of the Scientific Study of Religion, v. 37, 1998.

GREIMAS, A. J. Semântica estrutural. Trad. Haquira Osakabe e Izidoro Blikstein. São Paulo: Cultrix: Edusp. 1973.

Sémantique structurale: recherche de méthode. Paris: Larousse, 1966.

; COURTÉS, J. Dicionário de semiótica. Trad. Alceu Dias Barbosa Lima et al. São Paulo: Contexto, 2008.

KASTENBAUM, Robert; AISENBERG, Ruth. Psicologia da Morte. São Paulo: Pioneira, 1983.

KELLEHEAR, Allan. Uma história social do morrer. Trad. Luiz Antônio Oliveira de Araújo. - I Ed. - São Paulo: Editora da Unesp, 2016.

KLEIN, R. The human career: human biological and culture origins. 3. ed. Chicago: University of Chicago Press, 2009.

KOVÁCS, Maria Júlia. Representações de Morte. In: KOVÁCS, Maria Júlia (Org.). Morte e desenvolvimento humano. 4. ed. São Paulo: Casa do Psicólogo, 1992.

KUTSCHERA, Franz Von. Sprachphilosophie. Munique : Fink, 1971.

LARSON, C. S. Biological changes in human population with agriculture. Annual Review of Anthropology, v. 24, 1995.

LEWIN, R. Human Evolution: an illustrated introduction. Malden: Blackwell Science, 1999 . 
LUCAS, G. M. Of death and debt: a history of the body in Neolithic and Early Bronze age Yourkshire. Journal of European Archaeology, v. 4, 1996.

MORIN, Edgar. O homem e a morte. Lisboa: Europa - América, 1997.

MURILLO, José Ignácio. El valor revelador de la muerte - estudio desde Santo Tomás de Aquino. Cuandernos de Anuario Filosófico de la Universidad de Navarra, 1999.

ORLANDI, Eni P. Análise de discurso: princípios e procedimentos. 12. ed., Campinas, SP: Pontes Editores, 2015.

PLATÃO. Fédon. Trad. Jorge Paleikat, José C. de Souza, João Cruz Costa. São Paulo: Editora Nova Cultural, 1991.

SANTAELLA, Lucia; Nöth, Winfred. Imagem: cognição, semiótica, mídia. São Paulo: 1997; lluminuras - reimpressão 2015.

SCARRE, C.; FAGAN, B. M. Ancient civilizations. Upper Saddle River: Prentice-Hall, 2003.

STERNBERG, Robert J. Psicologia Cognitiva. Trad. Maria Regina Borges. Porto Alegre: Artmed, 2000.

WITTGENSTEIN, Ludwig. Investigações filosóficas. 9. ed. Petrópolis: Vozes, 2014. 